\title{
Effect of Hybridization of steel fibers on the mechanical properties of high strength concrete
}

\author{
M. Iqbal Khan ${ }^{1, *}$ and Wasim Abbass ${ }^{1}$ \\ ${ }^{1}$ Professor, Department of Civil Engineering, King Saud University, Riyadh, Saudi Arabia \\ ${ }^{2} \mathrm{PhD}$ Student, Department of Civil Engineering, King Saud University, Riyadh, Saudi Arabia
}

\begin{abstract}
The hybridization of fibers for arresting the crack in concrete is a key factor and play an important role to improve mechanical properties of high performance concrete with respect to mono fibers. The effect of hybridization of hooked end steel fibers with different length and diameter on mechanical properties of high strength concrete was investigated in this research work. The different percentages of hook ended fibers $(60 \mathrm{~mm}$ and $40 \mathrm{~mm}$ ) are hybridized in the concrete mixture while keeping total percentage of fibers by volume equal to $1 \%$. The compressive and flexural properties with complete load verses deflection curves of hybrid steel fiber reinforced high performance concrete were investigated to find the optimized dosage of hybrid steel fibers. The results showed that the hybridization of fiber provided better compressive and flexural performance. It was also observed from the results that combination of $65 \%$ of $60 \mathrm{~mm}$ and $35 \%$ of $40 \mathrm{~mm}$ hooked end fibers proved to be best for enhancement in compressive and flexural properties.
\end{abstract}

\section{Introduction}

Concrete is widely used construction material due to its diversity and easiness in different application but still has an eye catching drawback of very low capacity to deflect due to high brittleness, fortunately, this disadvantage of high brittleness and low resistance to crack formation can be catered using short random fibers [1]. Addition of fiber to concrete is to compensate for tension in concrete; this resulting material is commonly referred to Fiber Reinforced Concrete (FRC). These improved tensile characteristics of concrete comprise increased toughness, increased strength, improved matrix stiffness, higher ductility, hardening behavior in the post-cracking response compare to plain concrete, normally also named as high performance fiber reinforced concrete (HPFRC) $[2,3]$. The technique of combining the different fibers to achieve their maximum efficiency in the concrete is known as hybridization. Hybrid fiber reinforced concrete is not just the addition of different fiber but these different fibers are added to achieve the new composite with enhanced properties of concrete. This optimization process of different fibers for positive interaction between the fibers is commonly termed as "synergy". Different researcher have made a lot effort to identify synergy by optimizing the fiber ratio [4-10]. Optimization of fiber for synergetic effect for flexural and direct tension are reported [11, 12]. Whereas, in some of the cases, there was no synergetic effect was observed due to influence of matrix and in some cases synergy was found under certain loading such as shear [13]. This research work presented herein is focused on finding the synergy of fibers in terms of compressive strength, flexural strength, displacement capacity. Hooked end steel macro fibers long and short are combined to different percentage ratio to maximum of $1 \%$ steel fibers in concrete by volume and their effect on the mechanical properties of high performance concrete is investigated.

\section{Materials and Methods}

\subsection{Cement}

ASTM Type I, Ordinary Portland cement (OPC), from local cement plant was used. The chemical composition of the cement used in this study is presented in Table 1.

\subsection{Admixture}

High-range water-reducing (HRWR) modified polycarboxylate based super plasticizer conforming to the requirements of ASTM C494 type F was used.

\subsection{Fine and Coarse Aggregates}

Two types of sands with different particle sizes were used for preparation of mixes named as crushed sand and fine sand. Fineness moduli are 1.47 and 4.66 for fine and crushed sand respectively. Fine and crushed sand were combined to achieve fineness modulus of 2.54. Coarse aggregate with maximum size of $10 \mathrm{~mm}$ is used for preparation of concrete mixtures.

* Corresponding author: miqbal@ksu.edu.sa 
Table 1. Chemical composition of cement.

\begin{tabular}{|c|c|}
\hline $\mathrm{SiO}_{2}$ & $20.2 \%$ \\
\hline $\mathrm{Al}_{2} \mathrm{O}_{3}$ & $5.49 \%$ \\
\hline $\mathrm{Fe}_{2} \mathrm{O}_{3}$ & $4.12 \%$ \\
\hline $\mathrm{CaO}$ & $62.43 \%$ \\
\hline $\mathrm{MgO}$ & $0.71 \%$ \\
\hline $\mathrm{SO}_{3}$ & $2.61 \%$ \\
\hline $\mathrm{Na}_{2} \mathrm{Oeq}$ & $0.26 \%$ \\
\hline Loss on ignition & $1.38 \%$ \\
\hline Specific gravity & 3.14 \\
\hline Fineness m${ }^{2} / \mathrm{kg}$ & 373 \\
\hline
\end{tabular}

\subsection{Fibers}

Two different hooked ended steel fibers were used in this study. Hooked ended steel fibers were normally used for steel fiber reinforced concrete. Therefore, two different lengths of steel fibers with various diameters were proposed for this work. The tensile strength and Young's modulus of the used steel fibers were 1250 $\mathrm{MPa}$, and $210 \mathrm{GPa}$ respectively. Other properties of the used steel fibers are summarized in Table 2.

Table 2. Properties of hook ended steel fiber.

\begin{tabular}{|c|c|c|c|}
\hline & $\begin{array}{c}\text { Length } \\
(\mathrm{mm})\end{array}$ & $\begin{array}{c}\text { Diameter } \\
(\mathrm{mm})\end{array}$ & $\begin{array}{c}\text { Aspect ratio } \\
(1 / \mathrm{d})\end{array}$ \\
\hline 1 & 40 & 0.62 & 65 \\
\hline 2 & 60 & 0.75 & 80 \\
\hline
\end{tabular}

Total seven different concrete mixes with different combination of two fibers were prepared. In the mix design, water/cementitious ratio of 0.30 and the slump of
$150 \pm 25 \mathrm{~mm}$ were chosen for concrete without fibers. Fibers with two different lengths (40 and $60 \mathrm{~mm}$ ) and with two different diameters $(0.62$ and 0.75$)$ were used in the mixes. Mixes were designated as M-A, M-B, M-C, $\mathrm{M}-\mathrm{D}, \mathrm{M}-\mathrm{E}$ and $\mathrm{M}-\mathrm{F}$ and Control. The quantities for each mix are presented in Table 3.

All aggregates were added to the mixer and mixed for few revolutions with absorption water of aggregates and then cement was mixed in dry state for few minutes. Premixed super plasticizer with water was added to the aggregates. All the materials were mixed for three minutes followed by a rest of three minutes then mixing again for two minutes. The mixer was stopped and the concrete mixture was casted in different molds according to the specimen sizes. For fiber reinforced concrete, fibers were added to concrete after the preparation of concrete mixture and mixed for five minutes for well dispersion of fibers in the concrete.

Concrete cylinder specimens of 100 x $200 \mathrm{~mm}$ were cast for standard compressive strength test in rigid plastic molds. Specimens of 75 x 75 x $300 \mathrm{~mm}$ were prepared for the flexural strength of fiber reinforced concrete. Flexural specimens were casted in two layers and vibration was done for 15-20 seconds for each layer. The top surface of the specimen was smoothened with trowel and the specimens were covered with plastic sheet to maintain moist condition. The specimens were demolded after 24 hours and cured under $100 \%$ relative humidity at temperature of $22 \pm 2 \mathrm{oC}$ until the age of testing.

Compressive strength of concrete was measured by using cylinder of $100 \times 200$ under Tonitech compression testing machine and flexural specimen were tested using INSTRON model 3367 at a loading rate of $0.2 \mathrm{~mm} / \mathrm{min}$ for recording the post peak behavior of fiber reinforced concrete as shown in Figure 1.

Table 3. Mix proportions in a ratio form for all mixes.

\begin{tabular}{|c|c|c|c|c|c|c|c|}
\hline & M-A & M-B & M-C & M-D & M-E & M-F & Cont. \\
\hline Description of Mix & $\begin{array}{c}\text { Mono } \\
(60 \mathrm{~mm})\end{array}$ & $\begin{array}{c}0.75+ \\
0.25\end{array}$ & $\begin{array}{c}0.65+ \\
0.35\end{array}$ & $\begin{array}{c}0.5+ \\
0.5\end{array}$ & $\begin{array}{c}0.25+ \\
0.75\end{array}$ & $\begin{array}{c}\text { Mono } \\
(40 \mathrm{~mm})\end{array}$ & Null \\
\hline $\mathrm{kg} / \mathrm{m}^{3}$ & $\mathrm{~kg} / \mathrm{m}^{3}$ & $\mathrm{~kg} / \mathrm{m}^{3}$ & $\mathrm{~kg} / \mathrm{m}^{3}$ & $\mathrm{~kg} / \mathrm{m}^{3}$ & $\mathrm{~kg} / \mathrm{m}^{3}$ & $\mathrm{~kg} / \mathrm{m}^{3}$ \\
\hline Cement (OPC) & 500 & 500 & 500 & 500 & 500 & 500 & 500 \\
\hline Steel Fibers (short) & 0.0 & 19.62 & 27.4 & 39.2 & 58.8 & 78.5 & 0.0 \\
\hline Steel Fibers (Long) & 78.5 & 58.8 & 51.0 & 39.2 & 19.6 & 0.0 & 0.0 \\
\hline Aggregate 10mm & 1052 & 1052 & 1052 & 1052 & 1052 & 1052 & 1052 \\
\hline Sand (Crushed sand) & 251 & 251 & 251 & 251 & 251 & 251 & 251 \\
\hline Sand (White sand) & 467 & 467 & 467 & 467 & 467 & 467 & 467 \\
\hline water & 164 & 164 & 164 & 164 & 164 & 164 & 164 \\
\hline
\end{tabular}



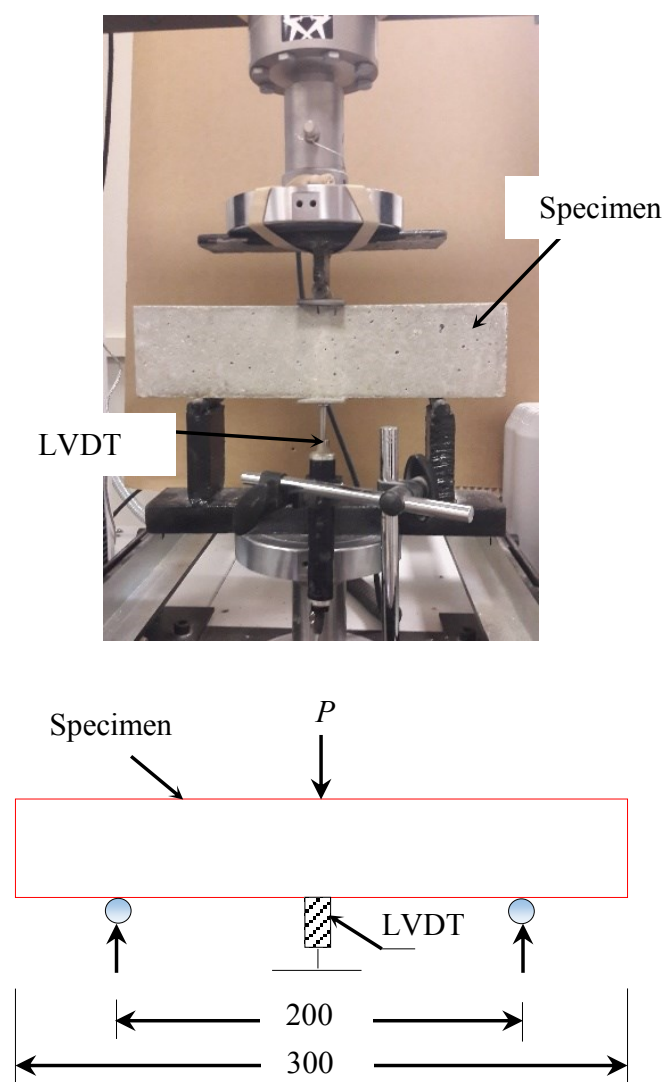

Note. All dimensions are in $\mathrm{mm}$

Fig. 1. 3-Point flexural test setup and schematic diagram for concrete and SHCC specimens.

\section{Results and discussion}

The results for the compression test conducted for plain concrete and SFRC with different percentages of steel fibers are present in Figure 2. An increase in compressive strength with addition of fibers is observed. Results also revealed that compressive strength of concrete increase $4-8 \%$ for mono and hybrid steel fibers. Whereas for mono fiber mixes, the increase in strength was almost identical but there is optimum hybrid mixture which gives maximum increase in compressive strength of $8 \%$. This increase in compressive strength may be attributed due to ability of fiber to delay the formation of crack [14].

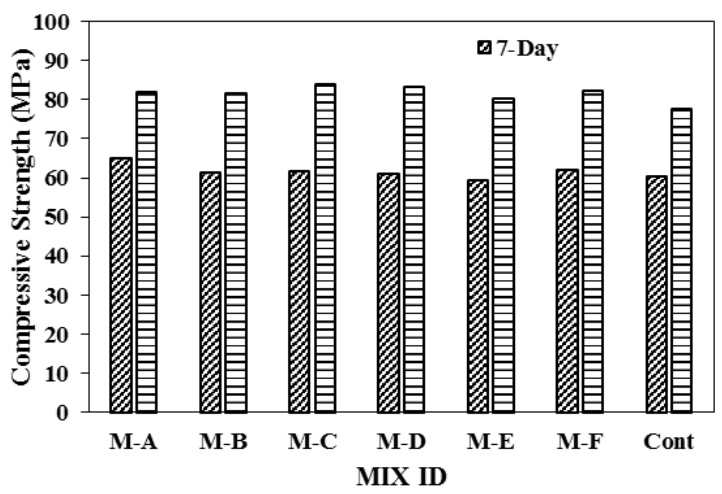

Fig. 2. Compressive strength of hybrid fiber reinforced concrete.
The flexural test results obtained from three point loading using set up described in above section are presented in Figure 3 and Figure 4. The results are described as load vs deflection at two ages at 7 days and 28 days in Figure 4. The peak stress on the load deflection curve was calculate by $\sigma=(3 P L) /\left(2 \times b \times d^{2}\right)$, where: $\sigma$ is flexural strength, $\mathrm{P}$ is peak load, L span length of prism, $\mathrm{b}$ is width of specimen and $d$ is depth of the specimen. The increase in the flexural strength for different combination of hybridization is shown in Figure 3. It can be observed that increase in the flexural strength of mixture with fibers reached to $60-100 \%$ with the variation of combination of fibers as compare to plain concrete. Results have shown that the mono fibers has maximum increase in flexural strength up to $60 \%$ as compared to plain concrete whereas hybridization of fibers has increment in flexural strength up to $100 \%$. Maximum increase in flexural strength was observed for the mixture MC as compared to all other mixtures.

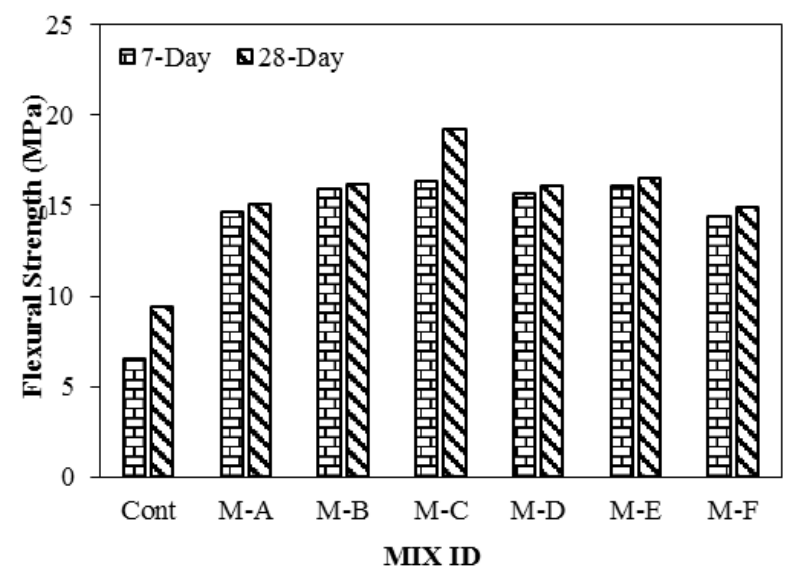

Fig. 3. Flexural strength of hybrid fiber reinforced concrete.

The load vs deflection behavior of steel fiber reinforced concrete using mono and hybrid steel fibers is shown in Figure 4. It can be observed from the result that peak flexural stress does not coincide with the first crack stress, which occurred earlier on the load deflection curves of all the mixture, therefore composite exhibits this behavior can be named deflection hardening of steel fiber reinforced mixture [15].

Figure 4(b) shows the load vs deflection behavior of different mixture composites at age of 28 days. The hybrid composite mixture have shown stronger behavior in terms of ultimate load, higher stiffness at postcracking stage and consists of better fracture toughness. The ultimate deflection of hybrid composites are also observed to be higher than mono fiber and plain concrete. It is also observed that the peak load for the mixtures with fiber with higher aspect ratio has higher value than that of lower aspect ratio fibers that may be attribute due to arrest of cracking after initial cracking and holding bond strength for longer length of fibers. Higher percentage dosage of long fibers in hybridization has increased the flexural performance, ultimate deflection, stiffness up to optimum dosage of hybridization (65\% long fiber and 35\% short length) as shown in Figure 4(b). 


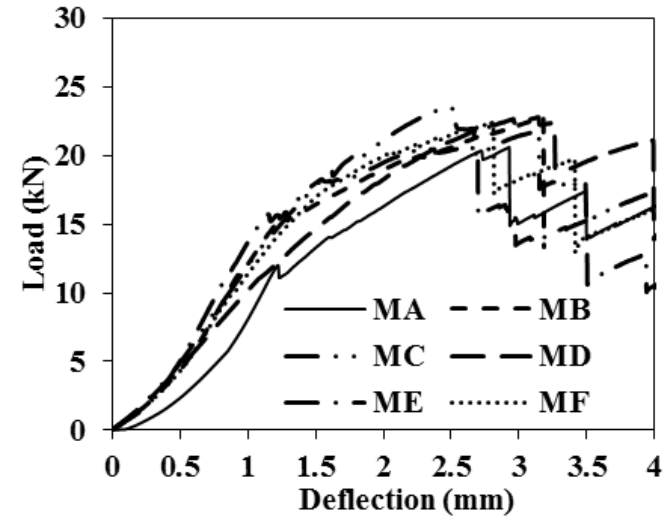

(a) SFRC at 7 days

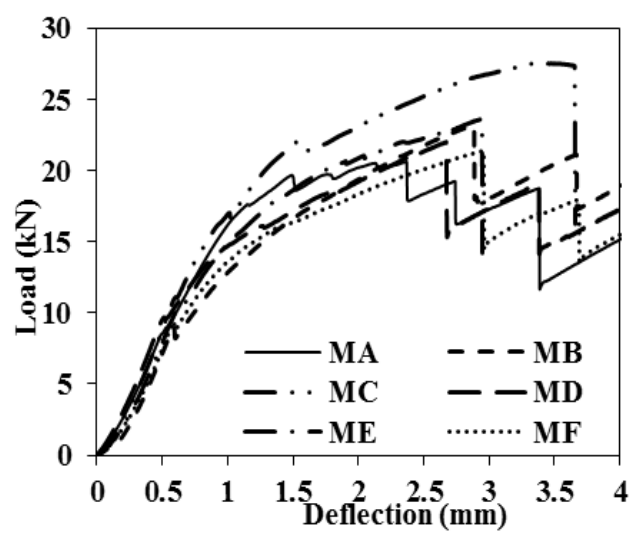

(b) SFRC at 28 days

Fig. 4. Load vs deflection response of hybrid steel fiber reinforced concrete.

\section{Conclusions}

Properties of plain and steel fiber reinforced concrete with mono and hybrid fibers have been examined in this paper under compression and flexural tests. Hybridization of fibers was done on the same total volumetric ratio of fibers for concrete mixture. Following results can be concluded based on the experimental observation:

The maximum increase in compressive strength of $4-8 \%$ was observed with the addition of hybrid fibers to plain high strength concrete. There is no significant effect of hybridization of compressive strength of concrete.

Peak bending stress and ultimate deflection increased due to the addition of fibers and even better flexural performance was observed using hybrid fibers. An increase in the flexural strength of mixture with fibers reached up to $60-100 \%$ with the variation of combination of fibers as compare to plain concrete.

\section{References}

1. A. Bentur, S. Mindess, Fiber Reinforced Cementitious Composites, Taylor and Francis (2007)

2. P.N Balaguru, S.P. Shah, Fiber Reinforced Cement Composites, McGraw Hill, New York (1992)

3. G. Fischer, V.C. Li, Eng. Fract. Mech., 74, 258-272 (2007)

4. N. Banthia, M. Sappakittipakorn, Cem. Conc. Res., 37(9), 1366-1372 (2007)

5. A. Bentur, S. Mindess, Fiber Reinforced Cementitious Composites, Elsevier Applied Science, London (1990)

6. G. Xu, S. Magnani, D.J. Hannant, Cem. Conc. Comp., 20(1), 79-84 (1998)

7. N. Kistaiah, C.U. Kiran, G.R. Reddy, M.S.,Rao, J. Reinf. Plast. Compos. (2014)

8. L.G. Sorelli, A. Meda, G.A. Plizzari, ASCE J. Mater. Civ. Eng. 17 (1), 519-527 (2005)

9. L. Cominoli, A. Meda, G.A. Plizzari, In: Adv. Constr. Mater., Springer Science-Business Media (2007)

10. Y. Mohammadi, S.P. Singh, S.K. Kaushik, Constr. Build. Mater. 22(5), 956-965 (2008)

11. N. Banthia, S.M. Soleimani, ACI Mater. J., 102(6), 382-389 (2005)

12. E.B. Pereira, G. Fischer, J.A.O. Barros, Cem. Conc. Comp., 34(10), 1114-1123 (2012)

13. N. Banthia, F. Majdzadeh, J. Wu, V. Bindiganavile, Cem. Conc. Comp., 48, 91-97 (2014)

14. M. Şahmaran, O.I. Yaman, Constr. Build. Mater., 21, 150-156 (2007)

15. A.E. Naaman, H.W. Reinhardt, Mater. Struct., 39(5), 547-555 (2007) 